\title{
The Centrality of Sustainable Well-Being of Humans in Sustainable Development
}

\section{Lindsay Hughes ${ }^{1, *}$, Esther Wangari ${ }^{2}$}

1 Affiliate Faculty, Center for Health and Risk Communication, Department of Communication, George Mason University / 4400 University Drive, MS 3D6, Fairfax, VA 22030, USA

2 Associate Professor, Women's and Gender Studies, Towson University / 8000 York Road, Baltimore, MD 21252, USA

E-Mails: 1hughes5 @ gmu.edu (L.H.); ewangari@gmu.edu (E.W.)

* Author to whom correspondence should be addressed; E-Mail: lhughes5@gmu.edu; Tel.: +1-301-968-6802

Received: 14 September 2013 / Accepted: 31 October 2013 / Published: 01 November 2013

\begin{abstract}
International policy has shifted focus in recent years toward sustainable health and development initiatives prioritizing capacity strengthening, country ownership in response to criticism of paternalism and imperialist objectives identified in postdevelopment theory. Subsequent interventions focus on issues related to basic needs, as opposed to explicit economic policy, but fail to adequately address structural issues that threaten sustainability. Women are frequently tokens of empowerment, but are not given tools to achieve upward mobility - this discursive display may actually worsen the reproduction of inequality. This article examines development policy to date, with an eye toward sustainable development and through the lens of critical feminist post-development theory. Demonstrated through case studies and discussion, we contend sustainable development is possible only when sustainable well-being of humans is prioritized ahead of symbolic or macro-level policies. We advocate for citizen-driven processes to operationalize well-being, enabling a disaggregation of the multiple components that community members identify as threats to the sustainability or acceptability of development initiatives. Personally-identified components of well-being collected via selfreport offer an opportunity for validation and analysis across multiple programs, and could lead to the identification contextually appropriate strategies to address social and environmental instability.
\end{abstract}


Keywords: gender; information access; policy; barriers; class; race

\section{Introduction}

The concept of development in its current form - a multi-faceted process of reorganizing or reorienting numerous societal structures, attitudes, and institutions, including economic, political, societal, healthcare, agricultural, and industrial domains (4) - first entered the lexicon amid a call for mobilization to lift up "underdeveloped nations" in a context of capitalist protectionism (2). Based on the belief that poor nations would be drawn to Communism, security by way of nation-building and modernization was an important Cold War Strategy (1). Likewise, the Soviet-bloc supported states using a similar strategy, disrupting a capitalist take-over (3). To reinforce the security of capitalism by regulating markets, bolster and secure international trade, and create more consumers, as well as to avoid protectionism the World Bank and International Monitary Fund (IMF) were established as policy and financial institutions (4). The two foundational goals of development as it was initially conceptualized are to create consumers by modernizing "underdeveloped" economies and bringing them into the global economy, and to provide aid for crisis situations with the eventual hope that those citizens would, too, join the global economy (3).

Though development's core value is protection of the global economy and proliferation of capitalism, it is indeed a multi-faceted endeavor. Some facets, such as agriculture and industry, are directly connected to the participation of developing nations in the global capitalist economy. Others, such as health care, community and social issues, nutrition, hygiene, and access to basic needs, have a more altruistic nature and less obvious ties to solely the development of the economy. Sustainable development should be understood in this context. Intruduced in 1987, the UN called sustainable development "development that meets the needs of the present without compromising the ability of future generations to meet their own needs" (5). The call for sustainable development has increased in recent years, framed by the International Institute for Sustainable development as "environmental, economic, and social well-being for today and tomorrow" (6).

Development policy has undergone numerous shifts since the mid-twentieth century. Recent years have seen a shift from the conceptualization of development as "aid" to the creation of sustainable interventions, developing the capacity of indigenous activists and providers, and country ownership of strategies and interventions. The need for a relationship between foreign donors and partner country governments that is mutually respectful and collaborative is central to The Paris Declaration on Aid Effectiveness, which posits that sustainable development is only possible if the donor community commits to respecting the leadership of partner countries in setting priorities and designing national strategies (13).

Critics of development question whether an actual shift occurred, suggesting that it is merely a rebranding of imperial and colonial hegemony (9) (8). Post-development theorists criticize the imposition of modernity and progress, as defined by wealthy Western powers, emphasizing the need for social change to be initiated and moved organically through social movements and political processes consistent with local traditions and beliefs (12).instead of change from withinwithout the identify development as necessarily disruptive of traditional and indigenous culture in its effort to modernize societies impose an idealized, ethnocentric economic, political, and cultural worldview 
policy as vehicles of control to further the interests of donor nations through the commodification of labor, colonization of knowledge, imposition of racial, gendered, and class division, is a social construct that obscures is a continuation of many of the mechanisms of control used by its predecessors, including othering, paternalism, and the implication of deficiency of developing nations (3). This othering adversely affects the well-being of members of developing state, reducing their agency, negatively impacting individuals' sense of self-efficacy, and imposing a hierarchy of humans based on national borders (8) (13).

Notably, the United Nations Millennium Development Goals (MDGs), which were established in 2000, have been adopted by UN member nations and are a driving force in sustainable development efforts and policy. The eight MDGs cover various priorities aimed at meeting the needs of the poorest people in the world, and include the eradication of extreme poverty, access to education, and elimination of specific diseases such as HIV/AIDS and malaria (14). Further, the rhetoric of The Paris Declaration may be looked to as a turning point in the recent history of development toward sustainability. The empowerment of local governments and civil society represents an important discursive shift toward a reduction in the imperialistic nature of Western involvement in developing countries. However, "sustainable development" is a vague term, and it is easy to avoid its root when assigning it meaning. A departure from development and a prioritization of the sustainable well-being of humans is a precursor to meeting the MDGs, from the alleviation of poverty to maternal health. Further, achieving the targets set in the MDGs is impossible without first addressing issues that are vital to poverty and oppression, especially the relationship between gender and power, including the issue of cathexis (or personal and emotional investment in a relationship or an idea), access to information, transportation to school and medical facilities, and an attempt to sustainably address gender dynamics, racial, and class issues.

\section{Learning from history to foster change}

To effectively engage with the development apparatus, to advocate for change, set targets, and identify appropriate partners, all the while setting reasonable expectations as citizens and voters, we must be cognizant of the values and purpose of the donor. To understand the historical context of a policy, one is well-served to examine the rhetoric of a given period for the presentation of the valueadded by leaders at that time. Policies of prescriptive, paternalistic social engineering correspond with a goal of stabilizing and controlling during Cold War fear; politicized foreign aid aimed at protecting U.S. interests was generous and resulted in support and hope for improvement because United States citizen altruism was bolstered by their belief that this investment resulted in their indirect protection from the "communist threat" (1) (9). More austere financial conditions coincided with more strict, and resultantly harmful, policies being tethered to the receipt of loans; a rise in Conservatism in the United States, the reduction of Cold War-era fear, and the lack of the average citizen to see a direct gain from their investment ushered in policies under the Washington Consensus, Structural Adjustment Policies, and efficiency-driven economic ideologies (8) (13) (3).

Considering the apparent relationship between political attitudes and global development policy, it is critical to analyze the assumptions that underlie even progressive strategies that place value on collaboration and desires of developing partner nations. Likewise, it is crucial to critically ascertain the fundamental goals of various donor organizations. The World Bank and IMF focus on the elimination of poverty and improving lives is focused on a macro-level scale. Country ownership and participation 
in this context has been prioritized to reduce the donor-driven nature and to create a space for the engagement of representatives from civil society to articulate needs more representative of the population as national strategies are set. However, Civil Society Organizations (CSOs) complain that they are not truly able to influence the agenda and are relegated to issues that they deem peripheral, such as healthcare and social issues (14) (15). The certainly is a challenge. The issue of inclusion in dialogue is complicated by the nature of the discussion, the shifts in outcome that are actually possible, and the ability - even if invited - for some people to actually participate in the conversation. We argue that attempts to solve the problems faced by the poorest citizens of the poorest nations must begin with a focus on the sustained well-being of humans. To achieve such a focus, targeted discussions, instead of simply inclusive ones, must be prioritized. The limitations of current efforts to participation are discussed in detail in ActionAid report on the limitations of CSOs in participating in discussions that have been established in an effort to increase participation and country ownership on the drafting of Poverty Reduction Strategy Papers (PRSPs) (15). In this report, the authors list topics which were censored at various meetings to set the agenda for drafting these papers, which feed into economic development strategies. Among censored topics are requests to consider alternative economic strategies, questions on the acceptability of privatization versus public service, and fundamental questions about the appropriateness of market-based strategy; one can see the importance of such elements being understood, but can also imagine the perception that such questions regarding basic tenets of development economics, and economics in general may be perceived as distractions from the goal of these discussions. XXXX notes that participation in these conversations requires table manners, so to speak; in other words, a strong grasp of such economic principles is necessary to participate in these conversations, and experts and policy makers have little patience for explaining the basic assumptions that bring them to the table. We note that this is likely not a matter of censorship, but rather, the expectation that high-level engagement requires the possession of an admittedly rarified knowledge. This is further discussed in strategies proposed to move from rhetorical country ownership to active ownership. The acknowledgment that these policies are extremely complicated has an implication about the type of conversation that may be had and who can meaningfully contribute (14). We will discuss possible measures to decrease this "knowledge gap" below, but the possession of a basic understanding of those concepts being discussed is a pre-requisite for many highly technical spaces. It is unrealistic for members of CSOs to meaningfully engage in these discussions, especially since CSOs represent an umbrella of civil service entities with varying levels of education and different areas of expertise.

A particularly noteworthy "censored" topic that was mentioned in the ActionAid report is the quality of educators in certain educational systems (15). This important topic is not being brought to the correct audience. Engagement in the PRSP and economic policy-making level can allow elected officials and economic experts to engage around matters related to the economy writ large, and the understanding must be diffused that the goal is the inclusion of national priorities on a societal scale as it fits into the global economy. Important local matters are not the purview of these exercises, but they absolutely must be addressed. True participation and country ownership requires the sustained wellbeing of humans. Distinct, but related to, the importance of health in building a sound economy, the well-being of humans, including their access to basic needs, education, and tools that can be used toward legitimate upward mobility is foundational in achieving the targets of the Millennium Development Goals and achieving success and sustainability through ownership and capacity. 
Intensive research and consultation with the target audience - those who are meant to directly benefit from intervention - is critical in the short-term and sustained success of such interventions. Failure to do so can result in the failure of the intervention, or worse, a boomerang effect in which the situation is actually made worse by the intervention having the opposite effect of what was intended (16) (17). Scholarship across disciplines tells us that it is necessary to step outside of the dominant apparatus to achieve the change we desire, which includes the need to focus on persons instead of societies. Even sustainable development rhetoric is that of capitalism, referencing social, economic, and natural capital (6). Capital, which can be accumulated, implies a concept of ownership that is completely inappropriate to this context. In fact, in many of the regions where aid is most needed, it is the nature of capitalism that disrupted the communal norms of reciprocity that sustained human well-being in times of crisis throughout history (18). The commodification - of agriculture, industry, and labor - and entry into the market resulted in elimination of stockpiles and safety nets (9). A focus on capital will remain, but we argue two caveats: 1 . Social engineering to create a consumer base can cease to be the focus. "Emerging markets" have entered into modernization and material culture. Africa is reportedly at the center of the mobile revolution, and participation in the global economy has been established (19). The players in the agenda-setting and strengthening of the economy to reduce poverty may remain unchanged, but the power dynamics must be addressed. 2. Humanitarian efforts, which may feed into the economy, must be ideologically divorced from the capitalist paradigm. Efficiency, costeffectiveness, and quality of life will only truly improve with this in mind.

\section{Addressing power in development}

As discussed, a major criticism of development is its donor-driven nature. Specific examples of the disastrous impacts of a focus on donor priorities will be provided below, but let us first explore the factors related to donor-imposed structures. Even in the best scenario, in which donors develop contextually appropriate strategies with great situational familiarity, participant buy-in is crucial (OXFAM). But buy-in from whom? Some reports state that governments buy-in under duress, in desperation for loans (FRIDE). Social desirability bias obscures client buy-in (CITE). Donors can measure impact by monitoring targets and incentives, which are unpopular for many (FRIDE) but must prove investment for their tax payers. Country ownership and participation was meant to address this, but is problematic for many reasons. In addition to the challenges to ownership discussed above, the production of knowledge is another obstacle for country ownership and full participation. When locals are sufficiently conversant with the rarified technical knowledge required to come to the table with these discussions, mitigating issues of class permeate (KENYA EDUC). Furthermore, those who do have access to higher education have frequently been educated in the West. A true participation requires the improvement of educational resources in development countries. While development policy has included education, this has frequently resulted in the limitation of governments to invest in higher education, requiring a focus on elementary schooling (FRIDE). While this gets at access to basic education for all, it also undermines the ability for nations to develop their own knowledge repositories. A focus on education must be one of the targeted, subject specific conversations, and resources should be devoted to the development of specialized programs of study, research institutes, and think tanks (FRIDE).

This first step at addressing the balance of power is crucial. To reach its full potential, issues of race, class, and gender must not be ignored in either access to education or basic daily life. Women are 
frequently used as instruments of empowerment, but are not given actual tools to improve their lives (3). Measures of gender equity that cite female inclusion in the workforce or receipt of college degrees mask the fact that many of the basic requirements to achieve these successes are out of reach of many girls (20). The imbalance of gender must be addressed at all levels instead of in specific domains. This is especially crucial to well-being, especially as other power relations are addressed. Connell's Theory of Gender and Power, applied by Wingood and DiClemente to public health outcomes, offers a compelling case as to the applicability of micro-level foci on societal level improvements (21) (22). This theory posits that three social structures operate on the societal level (e.g. historic and sociopolitical forces) and the institutional level (e.g. family, school, work, and healthcare): the sexual division of labor, the sexual division of power, and the structure of cathexis. The sexual division of labor frequently constrains women's options for work, reducing their economic potential. The sexual division of power is financial, as well as related to opportunity, control over others, and being controlled. Cathexis has to do with social norms and affective behavior, impacting societal expectations of women tied to sexuality, the perception self, and valuation as relational versus individual (22).

Power relations and access along class lines cannot be ignored, which is frequently the case as class becomes somewhat amorphous in discussions of poverty. Harmful development outcomes have been the result of peasant-blaming and colonial favoritism across ethnicity or tribe has continued power implications that influence opportunity, lead to conflict, and fuel division or perceptions across favoritism by class today (see, for example, the comments questioning tribal or regional preference in the announcement about leadership of the The Finance Bank of Zambia at www.lusakatimes.com (http://www.lusakatimes.com/2010/02/22/jacob-mwanza-tipped-to-succeed-mahtani/).

If participation and country-ownership are to enable a more reasonable balance of power on a global scale, interpersonal and community power relationships must first be addressed. This is not something that can be achieved by inviting CSOs to listen in on meetings, but by supporting a society in the development of their own intellectual capacity and by allowing for he ownership of ideas instead of the promulgation of ideas that have been imported. This achievement will improve the ability for meaningful engagement at all levels.

In addition to the sustainability that may be enabled by mindful investment in infrastructures of knowledge and the attention to power dynamics of race, class, and gender, goals must be understood as they facilitate well-being. Well-being is an improvement on any single indicator to measure the quality of life gains achieved through development. Well-being includes good living conditions, overall satisfaction with life, quality of relationships, fulfillment, and the ability to cope with one's environment. This holistic measure of quality of life is defined as perceived by the individual (23). Collected through self-reports and validated with quantifiable biological indicators, this is globally useful because well-being is rooted in context and perception. With an economic element, it can fit well within the dominant ideology but allow for disaggregation of CSOs to specific functions. This also allows for the development of interventions and target setting as meaningful. A focus on wellbeing and bolstering the knowledge production can lead to successful ownership and foster "sustainable development" through common-sense interventions that account for all needs, instead of problematic application due to conflicting values.

Notably, the Millennium Development Goals are supported by organizations (within and in parallel to the United Nations) for health promotion, economic strengthening, education, etc. Secretary General 
Ban Ki-m (24) but environmental sustainability, maternal health, gender parity, and access to sanitation and education are underperforming compared to other more discrete targets, such as access to HIV treatment, reduction in poverty, and reduction of undernourishment (25). The achievements must not be downplayed, but the successes have an apparent tie to the economy (e.g. access to commodities). This contrasts with social support and more abstract elements like access to education and gender parity, which are necessary to achieve before other targets, such as prioritization of maternal health, can be achieved.

\section{A problem of motivation}

Just as rhetoric has shifted in international development, the underlying motivation has also changed over time while retaining some consistent threads of serving the interests of multiple stakeholders. Retrospective analyses make apparent that altruism has not been a consistent motivator or has appeared as the face of economic, state-building, political, colonial, industrial, as well as ethnocentric priorities. Corporate Social Responsibility (CSR) projects frequently paint a picture of altruism and community development, but this mask comes off with minimal examination. The findings herein underline the importance of examination of motivation and actual indigenous ownership, especially as these initiatives may be undertaken by members of industry with especially poor reputations for respect of humans and the environment in an effort to obtain good public relations and to highlight the ways in which the community is benefitting from their presence.

CSR projects undertaken by multi-national corporations are framed as sustainable development initiatives to benefit workers as well as the community in which the corporation does business (6).CSR-based projects aimed at community development have become increasingly common among mining companies in Africa; typically these projects include sponsorship of microcredit initiatives; infrastructure development, including road, water, and access to utilities; and access to education and healthcare (7). An evaluation of CSR projects in Tanzania conducted by Emel, Makene, and Wangari (2013) highlighted their failure to address needs related to well-being even as they invested substantial sums in seemingly common-sense solutions to improve quality of life in the communities. Selected findings related to the analysis of investments in a pipeline from Lake Victoria (with a cost of over US $\$ 1.2$ million) claiming benefits to members of every community through which the pipeline passes are demonstrative of the extreme limitations of such initiatives. The investigators found that water did not pump daily, resulting in a shortage because of no storage capacity; half of spigots found were not functional; when available, water required boiling unlike water from springs in the area; and restrictions on the use of the water to human consumption. Additionally, the rerouting of the water required villagers to travel further to access points than they would have had to travel to the water source; water was not made available to a nearby primary school. Astonishingly, the same mining company had taken land from this primary school, whose only toilet is now on the mining company's property, and built the school water-based toilet which was not functional due to the lack of water to the school.

This failure to accommodate the most basic needs of humans while claiming to improve lives of community members is common in many development interventions. While some examples, such as above, raise serious questions as to the motivation behind the intervention, even programs with unquestionably good intentions fail to account for basic well-being. 


\section{Conclusion}

Discursive empowerment has the potential to disempower and harm by enacting blame and stigma. This article advocates for scholars, activists, citizens, policy-makers, and members of industry to apply a critical lens to the recommendations and suggestions herein. We maintain that a lack of commonsense analysis leads to inefficient use of resources, can be detrimental to well-being, and can even harm via stigma. Country ownership and indigenous identification of the flow of need and implementation of rational strategies to address the foundational issues of well-being in order of necessity is required to ensure the sustainable well-being of humans, without which sustainable development is not possible.

\section{Conflicts of Interest}

The authors declare no conflicts of interest.

\section{References and Notes}

\section{Works Cited}

1. Voth, Daniel. An Overview of International Development Perspectives in History: Focus on Agricultural and Rural Development. s.l. : University of Arkansas Department of Sociology, 2004.

2. Sachs, Wolfgang. Development Dictionary: A Guide to Knowledge as Power. London : Zed Books, 2010.

3. Rai, Shirin. Gender and the Political Economy of Development. Cambridge : Polity Press, 2002.

4. Mason, Edward Sagendorph and Asher, Robert . The World Bank Since Bretton Woods. Washington : The Brookings Institution, 1973.

5. The Brundtland Commission. World Commission on Environment and Development's Report on Our Common Future. Oxford : Oxford University Press, 1987.

6. International Institute for Sustainable Development. [Online] 2013. www.iisd.org.

7. Organisation for Economic Co-operation and Development. The Paris Declaration on Aid Effectiveness. s.1. : OCED, 2005.

8. Black, Maggie. The No-nonsense Guide to International Development. Oxford: New Internationalist Publications, Ltd, 2009.

9. Thomas, Alan. Poverty and the 'End of Development'. [book auth.] Tim Allen and Alan Thomas. Poverty and Development: Into the 21st Century . Oxford : Oxford University Press, 2000, pp. 3-23.

10. Escobar, Arturo. Encountering Development: The Making and Unmaking of the Third World. Princeton : Princeton University Press, 1995.

11. Eisenstein, Zillah. Against Empire: Feminism, Racism, and the West. London : Zed Books, 2004.

12. United Nations. Millennium Development Goals and Beyond 2015. UN Website. [Online] October 2013. www.un.org/millenniumgoals/.

13. The Rise and Fall of the Washington Consensus as a Paradigm for Developing Countries. Gore, Charles. 5, May 2000, World Development, Vol. 28, pp. 789-804.

14. InterAction. Country Ownership: Moving from Rhetoric to Action. s.1. : InterAction, 2011.

15. Rowden, Rick and Irama, Jane Ocaya. Rethinking Participation: QUestions for Civil Society about the Limits of Participation in PRSPs. Washington : ActionAid USA/ActionAid Uganda, 2004. 
16. Ajzen, I and Fishbein, M. Understanding Attitudes and Predicting Social Behavior. Englewood Cliffs : Prentice Hall, 1980.

17. Avoiding the Boomerang: Testing the Relative Effectiveness of Anti-Drug Public Service Announcements Before a National Campaign. Fishbein, M, et al., et al. 3, 2002, American Journal of Public Health, Vol. 93, pp. 238-245.

18. Davis, Mike. Late Victorian Holocausts: El Niño Famines and the Making of the Third World. London : Verso, 2001.

19. Fox, Killian. Africa's mobile economic revolution. The Guardian. July 23, 2011.

20. Problems with Reporting and Evaluating Mining Industry COmmunity Development Projects: A Case Study from Tanzania. Emel, Jody, Makene, Madoshi and Wangari, Esther. 2012, Sustainability, Vol. 4, pp. 257-277.

21. Connell, R W. Gender and Power.

22. Consequences of having a physically abusive partner on the condom use and sexual negotiation practices of young adult African-American women. Wingood, G M and DiClemente, R J. 1997, American Journal of Public Health, Vol. 87, pp. 1016-1018.

23. National Center for Chronic Disease Prevention and Health Promotion Division of Population Health. Health Related Quality of Life. Atlanta: United States Centers for Disease Control and Prevention, 2013.

24. UN News Service. Millennium Development Goals are within reach, but stronger efforts needed. s.1. : UN News Centre, July 1, 2013.

25. The United Nations. The Millennium Development Goals Report 2013. New York: The United Nations, 2013.

26. Mining and community development: Problems and possibilities of local-level practice. Kemp, D. 2010, Community Development Journal, Vol. 45, pp. 198-218.

27. Cooper, Frederick and Packard, Randall. International Development and the Social Sciences: Essays on the History and Politics of Knowledge. Berkeley : University of California Press, 1997.

(C) 2013 by the authors; licensee MDPI, Basel, Switzerland. This article is an open access article distributed under the terms and conditions of the Creative Commons Attribution license (http://creativecommons.org/licenses/by/3.0/). 